\title{
Learning through a Reflection: Becoming an effective
}

\section{PhD supervisor}

\author{
Nikica Mojsoska-Blazevski, PhD \\ Associate Professor/Dean, School of Business Economic and Management \\ University American College-Skopje, Macedonia \\ Tel: +38975-232-792Ｅ-mail: nikica@uacs.edu.mk
}

Accepted: July 03, 2012 Published: September 03, 2012

Doi:10.5296/ijld.v2i5.2339 URL: http://dx.doi.org/10.5296/ijld.v2i5.2339

\begin{abstract}
The aim of this paper is to learn how to be a better or more effective supervisor through a critical reflection on my own supervisory experience. The importance of the effective supervision is highlighted in view of the established link between effective supervision and greater completion rates of postgraduate degrees, where the latter is main focus of higher education institutions/authorities in the last decade.

The reflection is used to not only to justify the way we were supervised, but to challenge it and find ways how we can improve our effective supervision. Several researchers argue that supervisors usually adopt the same supervisory practice and style as the one they experienced themselves as research students (Pearson and Brew, 2002; Lee, 2008; Wright et al., 2008), notwithstanding additional factors that might influence the effectiveness of supervision. Pearson and Brew (2002) argue that new supervisors should have an ability to critically reflect on their past experience as research student in light of the theoretical conceptions and research findings in the literature on supervision, a process called "a critical reflective journey" by Tait (2009, p.193).

The methodology for this research is based on the framework for effective supervision adopted by Engebretson et al. (2008) who establish eleven characteristics of an effective supervision. Parallel to the examination of each of those individual characteristics, I provide my insight into each characteristic by reflecting on my own experience.

The structure of the paper is as follows. Section 1 introduces the importance of an effective supervision in the modern educational environment, as well as the value that critical reflection brings to the learning. Section 2 provides a literature review of the characteristics of a good supervisor, along with a personal experience related to each of them. Section 3 concludes.
\end{abstract}

Key words: Reflection, Learning, Supervision, Students, Oversees

\section{Introduction}

The new policy-driven quantifiable expectations for postgraduate education introduce neo-liberal concepts of efficiency, economies of scale and the image of students as customers (Engebretson et al., 2008). The focus now moves towards broader skill formation of $\mathrm{PhD}$ 
(research) students, non-academic employment possibilities and the quality of education, the latter including on-time completion, student satisfaction, effectiveness of supervisors, etc. (Pearson and Brew, 2002; Deuchar, 2008). Hence the increasing pressure on universities and supervisors to adopt effective practices and ensure that students complete their research in a minimum time. Increasing number of universities are responding by structuring or amending the current supervisor development programmes, though it is not yet clear in which way to do that (Pearson and Brew, 2002).

Several researchers argue that supervisors usually adopt the same supervisory practice and style as the one they experienced themselves as research students (Pearson and Brew, 2002; Lee, 2008; Wright et al., 2008). In other words, we would become effective supervisors if we were effectively supervised, notwithstanding additional factors that might influence the effectiveness of supervision, for instance the motive behind the supervision (Hockey, 1996). Pearson and Brew (2002) argue that new supervisors should have an ability to critically reflect on their past experience as research student in light of the theoretical conceptions and research findings in the literature on supervision. Tait $(2009, \mathrm{p} .193)$ call this process "a critical reflective journey", that needs to be undertaken by teachers who would like to widen their self knowledge.

Given that I am currently involved in my first supervision, as a home-based, second supervisor for oversees research student, previous arguments imply that an important element of my development in effective supervisor should be undertaking a critical reflection on my own supervisory experience. This is exactly the aim of the current paper: to learn how to be a better or more effective supervisor through a critical reflection on my own supervisory experience. We do not use reflection to justify the way we were supervised, but to challenge it and find ways how we can improve our professional practice, in this case an effective supervision, as recommended by Davis (2003).

I proceed with exploration of the characteristics of an effective supervisor and reflect on each of these characteristics in order to establish whether I was effectively supervised and whether and in which elements of the supervisory process I can develop better practice.

\section{Characteristics of an effective supervisor}

Given that research findings suggest that the quality and appropriateness of supervision is one of the central factors for successful and on-time completion of a $\mathrm{PhD}$ degree (Hockey, 1996; Wright, 2007), we should understand what the characteristics of a good, effective supervisor are.

I base this literature review on, though not limit to, the framework for effective supervision adopted by Engebretson et al. (2008). In particular, by undertaking a comprehensive literature review on "good supervision", these authors establish eleven characteristics of an effective supervision. Given that some of those overlap, I regrouped the characteristics into nine. Parallel to the examination of each individual characteristic, I provide my insight into each characteristic by reflecting on my own experience.

\section{Realistic and early appraisal of student's (individual) needs}

Early assessment of student's knowledge and skills might help defining research area and topic that suits best the student's capabilities (Engebretson et al., 2008). This includes assessment of student's theoretical knowledge, knowledge about methodology and data acquisition, computer literacy, technical skills, and writing style, etc. Once the gap in the knowledge/skills is detected, student can be directed to an appropriate university department, to undertake some additional coursework, etc. The importance of early assessment might be heightened when 
supervising oversees student, coming from different education systems, different cultures, etc., as I was and as my current supervisee is. The following is my experience in this area:

I had some difficulty in learning and quickly adapting to the UK educational system. For instance, I come from a country with (as I call it) maximization culture in education (characteristic of all ex-socialist countries), where students would get higher grades if they fill-in more pages in the examination booklet, with an extensive writing style and a lot of repetition. Once we agreed with my supervisor about the area of my research, I was given a task from my supervisor to write a 5-page report/essay on what I know about the issue. And, thinking that "more is better" I wrote 8 instead of 5 pages report. Then I got my first "lesson" - my supervisor asked me to re-write and condense the report to 5 pages. Fortunately, I got used to the minimization culture quite early in my enrolment on the PhD programme, so that afterwards I did not have problems with the exams and assignments (of the required coursework) which all had word limits, or with the size and writing style of the dissertation. When I re-think that event, it is obvious to me that my supervisor intentionally wanted to check my writing style and to early on resolve any writing issues.

\section{Pedagogical focus}

Supervision can be understood as a teaching activity in that effective supervisors provide practical strategies and show students how to improve certain skills, for instance how to write a literature review, how to write the research proposal, how to collect and analyse data, how to write academically, etc. (Engebretson et al., 2008).

The nature of the pedagogical process changes as the student progresses in the research. Early in the research, students need support in defining topic, research design and data analysis, literature review and academic writing, as well as a direction in designing an achievable research project (Haksever and Manisali, 2000). This initial coaching results in a preparation of a research proposal, and then, as student master skills and gain confidence, the role of the supervisor changes to a less directional one. Towards the completion of the project, the supervisor takes a role of an examiner, undertakes proof reading, checks the clarity and strength of arguments and so on.

By conducting a qualitative research, several other authors also find that the character of the supervision and relationship between the supervisor and student changes over the course of the research (Acker et al., 1994; Deuchar, 2008; Lee, 2008). It implies that scaffolding, where supervisors provide more support at the beginning of the research and more hands-off approach afterwards, might seem appropriate strategy for supervisors.

Going back to the period when I was doing my PhD, I would say that my supervision was exactly as the one explained above in terms of the supervisor's role and strength of the supervision that I had been receiving at each stage of my research. In the initial stage, as soon as we decided upon the research topic, I started practicing my writing style. The approach used by my supervisor was a pedagogical one, in which he would have shown me what good academic writing is and how to develop it. This was mainly done by detailed comments on my written work, going to over-correction. I would receive so many comments and corrections per page on my written work, that there were times I wanted to cry. Still, all these corrections would have almost always come along with some nice (I would say, encouraging and motivating) words about the content of the written work, style, etc. Through this exercise I considerably improved my writing style, and I am as picky in writing requirements as my supervisor was with me. 
In a similar manner, though in a longer time span I developed my critical thinking and analytical skills. To be honest, until some time ago I was not aware that learning all these skills was not an ad-hoc process, as I was perceiving it then, but a well-established, systematic process adopted and used by my supervisor. It really worked. He would never say, "Next we have to learn ...", but things were moving smoothly and naturally.

Once I advanced in writing chapters of the dissertation and completed the empirical chapter, my supervisor switched his role to an examiner, going in detail through each chapter, detecting weak arguments and points, proposing ways for making the thesis more compact and consistent, proofreading, etc. In the final stage, we practiced the viva voce so that I can be well prepared for the real viva.

\section{Academic challenge, facilitation and validation}

Though students like to be challenged by their supervisor, through a critical and rigorous appraisal, the manner in which the criticism is communicated with students is important and might either be a motivating or a strongly de-motivating factor (Lindgreen et al., 2002). The criticism has to be constructive, proposing some alternatives for improvement, instead of being in a generalized form "such as 'read more' or 'write more concisely"' (Lindgreen et al., 2002, p.158). Besides the challenge and motivation, supervisors should also facilitate students, or emancipate them (Lee, 2008) through creating comfortable climate for exchange of ideas, debating, arguing, therefore helping students to intellectually grow through interactions with the supervisor.

According to Lee (2008), one of the main concepts in supervising doctoral students is that of critical thinking, that is encouraging students to question and analyse their own work and work of others, to evaluate human arguments and reasoning by using rational and logical criteria. Stevenson and Brand (2006, cited in Lee, 2008) acknowledge that critical thinking is a feature and tradition of western intellectual system, and not necessarily other educational systems. However, given that critical thinking is considered an integral part of the research process in the British academic system (Lindgreen et al., 2002), it implies that the system is implicitly build on the assumption that all candidates posses this skill.

After learning more about the academic writing, referencing, how to write an introduction, how to develop a paragraph, chapter, etc., I had to learn how to critically assess other authors' findings and how to construct a strong argument. This was something that unfortunately I had never previously come across and pay attention to during my previous education. The education system in my home country was (and still is) based on memorization and unsupported claims, instead of understanding, critical thinking, argumentation. After 16 years of education in a different system, I cannot say that I quickly developed this skill. My supervisor was very patient with me at times when I would report rather than think and assess. My initial literature reviews were like "this author said this, that author said that..." I admire the way in which my supervisor taught me this skill which was mainly through open, argumentative discussions, challenging questions, debating, encouraging me to think deeply, to reason and question.

In my opinion, I did develop the critical thinking skills and it helps me not just in my academic work, but also in everyday life; I consider this as one of the major benefits of doing a PhD in the UK.

Accountable management of the process of thesis completion 
Supervisors today are required, among others, to manage effectively the whole research degree process of their students given the stringent completion requirements (Acker et al., 1994; Lee, 2008). Supervisors are responsible for providing the necessary information to students: inform students about university requirements for preparation and submission of a thesis, stages, reporting requirements, format and administration of a research proposal, available resources such as library, computers, any study-skills support, good practices for collection and storage of data, etc. As managers, supervisors have to set long and short-term plans with students, to check progress, still ensuring that students have the ownership on the direction of the research and the research project in general. Though, given the long-term commitment of students (and supervisors) for doing the research, which is from 3 to 5 years, supervisors also have to be flexible in a case of unplanned event that might distress student's attention to the project. Watts (2008) argues that supervisors might help students that face unplanned and serious life issues by temporary altering their research schedule and supporting them in getting back on track.

Fulfilling the long-term commitment of doing a PHD in UK which was a 4-year project, was rather a difficult task for me and I needed a great support from my supervisor. Through my experience I learned more about managing projects which helps me today with smaller "projects". I learned that I need to break down that large, 4-year project into smaller, manageable blocks. The first step in managing the research project was preparation of the time frame section in the research proposal. Though it is only indicative one, as different things happen meanwhile (for instance, I had problems with data acquisition), you gain more confidence that you can complete the whole project, if you complete several smaller-size projects/objectives. So, at one point of time, we were concentrating on one issue/usually one chapter, considering it as a project on its own. We would make a monthly plan of activities and I had to report monthly on the undertaken activities. Back then, I thought of monthly reporting as an unnecessary bureaucracy and burdensome task for me, but today I held a view that plans and reports are a very powerful tool for successful management of the whole, long-term process, and put the necessary pressure towards students for progress especially in times when direct contact between the supervisor and student cannot be made.

However, unexpected interruptions do happen in this long-run project and the dynamic varies in different points of time. For instance, in during doing PhD, there were three different managers (in this case, ministers) in the institution where I worked. They were not all excited with their employee doing a PhD and having to be absent from work at least three months per year. I had some problems with this and I had to change our plan of work 2-3 times. Besides these professional interruptions, I experienced private ones, as well. I got married, gave a birth to a child, and my lifestyle changed considerably. Then, I had to make some break after child birth which changed our plan of work, fortunately not too much. In such situations, the supervisor has to be flexible and make some temporary amendments on the agreed project schedule.

Frequency and quality of meetings

Regular meetings or interactions between supervisors and students have positive effect on a successful completion of the research project (Engebretson et al., 2008). Though, the "right" frequency of the meetings might depend on the stage of the research. For instance, according to the Staffordshire University Research Supervision Module Guide (Adnett, 2009), it is expected that supervisors have regular contacts with students, with a higher frequency of meetings in the initial stage of research process when students need more structure and direction, slightly decline afterwards and increase in the late phase of project completion. Similarly, Beatty 
(2001) draws on her own experience with supervision and suggests that meetings at the beginning of supervisory process should be frequent.

Besides the frequency, the quality of the meetings also matter in terms of supervisor' preparedness for the meeting (read the written work, provided comments, etc). If we accept the importance of frequent meetings for the success of research students, then effective supervision of oversees distance-learning students might be threatened and supervisors in this case might adopt some strategies to overcome the potential problem.

According to Watts (2008), an important issue is also who initiates the direct contact. Although, university regulations require that supervisors are responsible for "maintaining regular contact with the student" (Adnett, 2009, p.31), this issue can be negotiated in the implicit learning contract between the two parties. Supervisors and students should also agree whether the students can meet the supervisor only in advance scheduled meetings, or might freely show up at the supervisor's office whenever in "urgent" need. Supervisors can decide to give their private phone numbers to students, or can insist only on e-mail contacts. For instance, in interviews with $\mathrm{PhD}$ supervisors about their own supervision experiences conducted by Lee (2008), some of them were reporting that once they have made a considerable progress or were very excited about the research project, they would want to immediately call or contact the supervisor.

In my opinion, it is important to find a balance between supervisor's availability and her/his other tasks and student's need for support or direction. This "balance" would be different in each supervisory process, but the two parties should negotiate in the early supervision the frequency of contacts, initiation, way of contacting each other (e-mail, telephone calls), suitable time for telephone or office contact, etc. I and my supervisor discussed this issue early in the supervision, and besides the scheduled meetings which were rather frequent at the beginning of supervision, I had a possibility for short, ad-hoc meetings when I needed quick direction. In addition, I would always get e-mail replies in at most one day. Such communication with supervisor prevents a possibility of waiting-time-periods when students need to discuss some issue with supervisor before proceeding, i.e. when they urgently need direction. Given that I would have stayed only 3 months per year at the University, I was working very hard during my stays there, so that I could not afford myself much rest instead of work. Though, I was fully aware that I should not be too demanding and expecting that the supervisor is equally excited with my research as I was, understanding that for supervisors supervision is only one of the job duties, whereas for students the research project is the sole or major task.

\section{Submitting written work}

Students should be encouraged to submit written work early in their programme enrollment so that the supervisor can assess student's writing skills and if necessary provide support. Based on their experience with supervision and being supervised, Reidy and Green (2005, p.57, in Engebretson et al., 2008) favour the "you write-I read-we meet" approach in their supervision, where a student prepares a written work according to the agreed plan of work and submits it to the supervisor. The supervisor would then give detailed feedback to the student which is discussed on the next meeting. They argue that adoption of such approach assists the successful completion of research projects. Beatty (2001) also argues that ideas have to be put on a paper before each meeting, whereas Lindergreen et al. (2002) quote a French author Boileau, stating that we can easily put on paper only things that we clearly conceive. From a student's perspective, putting their thoughts in writing is not an easy task "as these thoughts may have not been well conceptualized" (Lindergreen et al., 2002, p.153). 
I and my supervisor were working exactly in the manner that is suggested to be effective. Once we would schedule a meeting we would also agree the deadline for me to submit the written work. Then, on the meeting, the supervisor would give me his comments and we would discuss them and supervisor would make sure that I am clear with all the comments. We would debate if I disagree with some of them, and the most important thing was that at the end of the meeting I would have been clear about all comments and how I could implement them. Though, I was given the possibility to afterwards check again if something was not clear to me. We would also agree a time line for me to send the corrected written work. In addition, towards the end of each meeting we would discuss next short-term goal and timing of the next meeting. I am aware that supervisor's comments were essential to the success of my thesis.

Early in supervision I was asked by my supervisor to prepare agenda for each meeting and minutes from the meetings (this was part of our implicit learning contract). Honestly, at first I considered this "requirement" as a bureaucratic one. However, latter on, I found out preparation of agendas as very useful method of narrowing down and conceptualising my ideas. It was kind of a brainstorming process for me. Though sometimes agendas were quite poor, with one or two items like 'discussion on the latest submitted written work', there were times when the agenda would have been a collection of (for me) important questions, doubts, breaking points which were essential for the direction of my future work. Regarding the minutes from the meetings, again I found them very useful. In particular, they may act as student's and supervisor's long-term memory. At the meetings, when things are clarified and something is agreed, we think that we would certainly remember that afterwards. But it is much better to immediately write down the most important things discussed and agreed to avoid any future confusion or misunderstanding. In addition, writing minutes is very helpful in terms of re-thinking our discussion and checking whether I am clear about all items that we had on the agenda.

\section{Prompt and constructive feedback}

Kumar and Stracke (2006) argue that feedback is a powerful pedagogical tool, but the manner in which the feedback is provided and the tone of the feedback should be carefully determined. The feedback has to be timely, clear instead of confusing the student, should not non-argumentatively criticise the student's work, challenge, corrects, provokes ideas and thoughts. Otherwise, the feedback and supervisor's comments might de-motivate and/or de-focus students.

According to Ronnestad and Skovholt (1993), the nature of feedback changes with the candidate's progression: the initial confirmatory feedback is substituted with a corrective and clarifying feedback. In particular, in the initial stages of research, students are less ready for confrontation and hence a good supervisor would engage more in emotional supportive behaviour, including modelling, teaching, etc., than in confrontational one (Reising and Daniels, 1983). In addition, Grant (2005) argues that the supervisor should guide the student from the novice to maturity through a supportive interpersonal relationship, sensibly and with certain flexibility.

Similarly, Watts (2008) argues that the feedback needs to be given in a manner that is in line with the emotional stage of the student, which is more an emotion work than of pedagogical one. Wright et al., (2007) classifies supervisors in five different categories based on how they conceive their role and finds that one of those categories is the so-called 'Supportive Guides', which adapt their style to the emotional needs of a students and become "gentle" and "encouraging" when required, also depending on the stage of the project and student's personality. 
My experience is that I was given quite detailed feedback on all submitted written work, from correcting typos, to editing and substantial comments. The feedback was usually given in a constructive and challenging way, for instance with a question "is this consistent with the previous?" and similar. However, there was one event that brought me close to a breakdown point which I would like to elaborate on. It was early in the supervision process, I have been only about two months at the University, and I got from my supervisor comments on the submitted written work. I was stressed with too many comments (whole pages were full of supervisor's comments which were in hand written form), but the particular comment that had a very negative effect on me was "So what?". This was related to an argument that I thought was important for the topic/area examined. When I reflect on that "event", I would not say that the comment was improper, but the timing and the tone of the comment was certainly such. In particular, I was still trying to adjust to the new environment, culture, while at the same time eager to keep up with the required coursework and initial work on the research proposal, so I was emotionally very week. Maybe I was very good at hiding that and my supervisor could not see my true feelings and weakness, but what I learned is that supervisors need to be very careful at least in the initial stage of supervision, when they have to both get familiar with the candidate and establish a relationship with her/him. This especially applies to oversees students and female students, who, according to Haksever and Manisali (2000) need much greater pastoral care than other students.

Providing access to a research culture

One of the roles of a good supervisor is assisting in networking, as well as in preparation and presentation of papers and publications (Wright et al., 2007). Lee (2008) suggests that in this role of the supervisor implies an apprenticeship element in supervision, naming it "enculturation" (p.272). This role of a supervisor is heightened by the nature of the research, which is usually independent and hence the students are academically and socially isolated (Deuchar, 2008). Hence, the recent trends towards stimulating collegial and joint approaches to supervision, such as workshops for students with similar interests, $\mathrm{PhD}$ topics, or methodological approaches, conferences for groups of students, seminars for $\mathrm{PhD}$ students on specific topics, etc. (Engebretson et al., 2008).

Once I progressed with the thesis preparation, that is in the second year of doing PhD, my supervisor "introduced" workshops and conferences for students that had similar research projects and were from countries with similar economic and social systems. These workshops/conferences were held once per year, in different countries in the region and then our papers (which were mainly draft chapters from our dissertations) would have been published in the Staffordshire University Research Paper Series. Those workshops/conferences were excellent experience as we could have shared our ideas, project development, debate and argue on issues that were mutual in our projects. We would discuss methodological issues, theoretical considerations, data acquisition problems, etc., and hence avoiding making some research mistakes. At the same time, we were required to write our papers in a "publication" style which was very helpful for our future publication record. This was made possible given that my supervisor had few candidates with similar projects. We also had more general workshops organized by the University where we were presenting our projects and would receive suggestions and comments from our peers and from other professors than our supervisors. 
The next characteristic of a good supervisor is early negotiation of the relationship with the student. Watts (2008) emphasises the importance of supervision, arguing that supervision is primarily a relationship (and a process). In addition to deciding on frequency of meetings, initiation, etc., supervisors and students have to set the boundaries to their relationship, however here the expectations of both parties are likely to be different (Engebretson et al., 2008). While supervisors are interested more into intellectual aspects of the research and effective management of the whole process, which is their obligation according to the University requirements (see Adnett, 2009), students highly value advice, sympathy, encouragement, and broader support than a strict academic one. Given that this divergence in expectations might potentially lead to a conflict, a clear implicit contract about the roles and obligations of each side should be defined early in the supervision process. Though, the relationship might change and be re-negotiated and adapted to the supervision momentum (Deuchar, 2008).

As I already explained, early in the supervision we agreed with the supervisor about the main elements of our relationship, such as the frequency of meetings, initiation, flexibility and availability of the supervisor, etc. Our relationship was mainly formal though the supervisor was taking a pastoral role in that he would have started each meeting with how I feel, how my family is, whether I have some private issues, etc. I was also invited a few times for a dinner at the supervisor's home and would invite him for a dinner when he was visiting me. Though we set our learning contract at the beginning of the supervision, it was adapted to the supervision stage but also my emotional and physiological position. In particular, while doing the PhD I got married and gave a birth to one child and was defending the thesis at the end of 7-th month of pregnancy with the second child. I think I was still quite stable emotionally, but these changes in my private life necessarily influenced my involvement with the project. Few times we had to alter our research schedule, at least temporary, but a combination of my strong determination in completing the project on time and motivation and encouragement that I got from the supervisor resulted in a successful completion.

\section{Conclusion}

This paper established the link between effective supervision and greater completion rates of postgraduate degrees, where the latter is main focus of higher education institutions/authorities in the last decade. Given that we supervise as we were supervised (Wright et al., 2007), here I provided a literature review on effective supervision, trying to assess whether I could develop into an effective supervisor. The listed characteristics are not all of the characteristics examined in the literature, but are the ones that are most frequently cited. Each characteristic of an effective supervisor was accompanied by reflection on my own experience.

In summary, the reflection of my supervision suggests that I was effectively supervised. This might indicate that my future as a supervisor is bright. I learned from my experience about how to coach students in writing style, in designing and managing the project, I learned the importance of initial assessment of student's knowledge and needs, I learned that there is no one-size-fits-all supervisory style and that we have to be flexible to student's needs, and that supervision is a multifaceted and hence hard project for both supervisors and students. However, learning from my own experience, I would be more supportive to students, especially those coming from oversees, and provide more pastoral care to them. I would also be careful with the feedback that I give to the students which would be more in a form of encouragement and clarification, than confrontation.

\section{References}


Acker, S., Hill, T. and Black, E. (1994) Thesis Supervision in the Social Sciences: Managed or negotiated?. Higher Education, 28(4): p. 483-498.

Beatty, S. E. (2001) The Doctoral Supervisor-Student Relationship: Some American advice for success. The Marketing Review, No. 2: p. 205-217.

Deuchar, R. (2008) Facilitator, Director or Critical Friend?: Contradiction and congruence in doctoral supervision styles. Teaching in Higher Education, 13(4): 489-500.

Engebretson, K., Smith, K., McLaughlin, D., Seibold, C., Terrett, G. and Ryan E. (2008) The Challenging Reality of research Education in Australia and Implications for Supervision: A Review of the literature. Teaching in Higher Education, 13(1): p. 1-15.

Gatfield, T. and Alpert, F. (2002) The Supervisory Management Styles Model, in Quality Conversations, Proceedings of the $25^{\text {th }}$ HERDSA Annual Conference, Perth, Western Australia, 7-10 July 2002: p. 263.

Grant, B. M. (2005) Fighting for Space in Supervision: Fantasies, fairytales, fictions and fallacies. International Journal of Qualitative Studies in Education, 18(3): 337-354.

Haksever, A. M. and Manisali, E. (2000) Assessing Supervision Requirements of PhD Students: The Case of construction management and engineering in the UK. European Journal of Engineering, 25(1): p. 19-32.

Hockey, J. (1996) Motives and Meaning Amongst PhD Supervisors in the Social Sciences. British Journal of Sociology of Education, 17(4): p. 489-506.

Lee, A. (2008) How are Doctoral Students Supervised? Concepts of doctoral research supervision. Studies in Higher Education, 33(3): 267-281.

Lindgreen, A., Palmer, R., Vanhamme, J. and Beverland, M. (2002) Finding and Choosing a Supervisor. The Marketing Review, No. 3: p. 147-166.

Park, C., Hanbury, A. and Kulej, M. (2008) Postgraduate Research Experience Survey: Final report. York: Nigher Education Academy (at www.hea.ac.uk)

Pearson, M. and Brew, A. (2002) Research Training and Supervision Development. Studies in Higher Education, 27(2): p. 135-151.

Reising, G. N. and Daniels, M. H. (1983) A Study of Hogan's Model of Counselor Development and Supervise. Journal of Counseling Psychology, 30(2): p. 235-244.

Ronnestad, M. H. and Skovholt, T. M. (1993) Supervision of Beginning and Advanced Graduate Students of Counseling and Psychotherapy. Journal of Counseling \& Development, Vol. 71: p. 396-405.

Swanson, J. L. and O'Saben, C. L. (1993) Differences in Supervisory Needs and Expectations by Trainee Experience, Cognitive Style, and Program Membership. Journal of Counseling \& Development, Vol. 71.

Tait, K. (2009) Reflecting on How to Optimize Tertiary Student Learning Through the Use of Work Based Learning Within Inclusive Education Courses. International Journal of Teaching and Learning in Higher Education, 20(2): p. 192-197.

Watts, J. H. (2008) Challenges of Supervising Part-time PhD Students: Towards student-centred practice. Teaching in Higher Education, 13(3): p. 369-373.

Wright, A., Murray, J. P. and Geale, P. (2007) A Phenomenographic Study of What it Means to Supervise Doctoral Students. Academy of Management Learning \& Education, 6(4): p. 458-474. 